\title{
The Mere Anticipation of an Interaction with a Woman Can Impair Men's Cognitive Performance
}

\author{
Sanne Nauts • Martin Metzmacher • \\ Thijs Verwijmeren · Vera Rommeswinkel • \\ Johan C. Karremans
}

Received: 10 June 2010 / Revised: 2 March 2011 / Accepted: 30 July 2011 / Published online: 1 November 2011

(C) The Author(s) 2012. This article is published with open access at Springerlink.com

\begin{abstract}
Recent research suggests that heterosexual men's (but not heterosexual women's) cognitive performance is impaired after an interaction with someone of the opposite sex (Karremans et al., 2009). These findings have been interpreted in terms of the cognitive costs of trying to make a good impression during the interaction. In everyday life, people frequently engage in pseudo-interactions with women (e.g., through the phone or the internet) or anticipate interacting with a woman later on. The goal of the present research was to investigate if men's cognitive performance decreased in these types of situations, in which men have little to no opportunity to impress her and, moreover, have little to no information about the mate value of their interaction partner. Two studies demonstrated that men's (but not women's) cognitive performance declined if they were led to believe that they interacted with a woman via a computer (Study 1) or even if they merely anticipated an interaction with a woman (Study 2). Together, these results suggest that an actual interaction is not a necessary prerequisite for the cognitive impairment effect to occur. Moreover, these effects occur even if men do not get information about the woman's attractiveness. This latter finding is discussed in terms of error management theory.
\end{abstract}

Keywords Cognitive performance .

Executive functioning - Mixed-sex interactions .

Error management theory

S. Nauts $(\bowtie) \cdot$ M. Metzmacher $\cdot$ T. Verwijmeren ·

V. Rommeswinkel · J. C. Karremans

Behavioural Science Institute, Radboud University Nijmegen,

Montessorilaan 3, 6500 HE Nijmegen, The Netherlands

e-mail: s.nauts@psych.ru.nl

\section{Introduction}

"What are you doing? What's the matter? Be quiet, stupid!" he said to his heart. But the more he tried to be calm, the more labored grew his breath. (Tolstoy, 2003/1877, p. 27)

In Tolstoy's famous novel Anna Karenina, Levin walks up to a skating pond to talk to Kitty. Determined to make a good impression on the girl, his heart starts racing as he thinks of what to say to Kitty and tries to picture her. At the time he arrives at the pond, he starts stuttering and blushing and is even unable to recognize a friend that passes by.

Novels and movies frequently feature men who are trying hard to impress a woman but are completely depleted by their attempts, causing them to stumble, forget where they live, or, in Levin's case, stutter and fail to recognize a friend. Though these examples may seem far-fetched, recent research suggests that they contain a kernel of truth: men's cognitive performance is depleted after a short interaction with a woman, especially if the woman is attractive and men report trying to impress her (Karremans, Verwijmeren, Pronk, \& Reitsma, 2009). Interactions that require impression management are cognitively taxing because people need to exert effort to strategically control their behavior and monitor the impression they make (Vohs, Baumeister, \& Ciarocco, 2005). Thus, men's (but not women's) cognitive performance is impaired after an interaction with someone of the opposite sex because they are trying to make a good impression on her, and impression management is cognitively costly.

In Levin's case, however, it is not the actual interaction with Kitty that causes him to stutter: he was already depleted by the time he reached the pond. In everyday life, there are many such situations in which men merely anticipate an interaction with a woman (anticipated interactions) or in which they do not communicate with a woman face-to-face (pseudo-interactions) 
but do so via phone or the internet. In fact, these types of "pseudo-interactions" have become more and more frequent through the advance of the internet and mobile phones, to the point where $89 \%$ of college students use instant messaging (and have instant messaging programs turned on for an average of $10 \mathrm{~h}$ a day; Hu, Wood, Smith, \& Westbrook, 2004), and almost $30 \%$ of employees use instant messaging to communicate with customers or colleagues (Garret \& Danziger, 2008). Next to pseudo-interactions, there are many situations in which men expect an interaction with a woman (e.g., when waiting for a meeting with a new female coworker or before going on a blind date). Thus, from a practical point of view, an interesting question is if such pseudo-interactions and anticipated interactions with opposite-sex others lead to the cognitive impairment effect that has been found previously in studies in which males actually interacted with an opposite-sex other.

One important difference between actual interactions and pseudo- or anticipated interactions is that in anticipated interactions or pseudo-interactions, men frequently know little to nothing about the woman they are (going to be) interacting with. Men do not usually know if the female call center employee who contacts them about their car insurance is attractive, or whether their new accountant, with whom they have an appointment later that day, is single. It is unclear if men's cognitive performance would decrease in such an uncertain situation, as people generally only expend cognitive resources if they find doing so is worthwhile (Baumeister, DeWall, Ciarocco, \& Twenge, 2005; Wan \& Sternthal, 2008), and men do not readily engage in impression management if a woman has low mate value (Wilson \& Daly, 2004). The first goal of the present research was to examine if men's cognitive performance decreased after a pseudointeraction with a woman in the absence of clear information about her mate value.

There are several lines of research suggesting that men may expend their cognitive resources on an anticipated or pseudointeraction with a woman even if they have little to no information about her mate value. Men are likely to perceive relatively neutral situations in sexualized terms: compared to women, they have a higher sex drive (Baumeister, Catanese, \& Vohs, 2001), and they are so strongly attuned to sexual opportunities that they frequently overperceive women's sexual intent (Haselton \& Buss, 2000). According to error management theory (Haselton, 2003), evolutionary pressures shaped an adaptively biased system of judgment in men that minimizes the risk of missing mating opportunities, even though this means that men frequently invest resources in women who are not actually interested in them (Haselton \& Buss, 2000). In line with this, there is research suggesting that even subtle exposure to a woman can trigger men's motivation to make a good impression, and could already instigate processes related to impression management (e.g., risk taking behavior; Ronay \& Von Hippel, 2010; Van den Bergh \&
Dewitte, 2006; Van den Bergh, Dewitte, \& Warlop, 2003; Wilson \& Daly, 2004). Thus, men are likely to be motivated to invest precious cognitive resources even in the absence of information about their interaction partner, because she might be an attractive mate. Therefore, we expect that men's cognitive performance will decrease after a pseudo-interaction with a woman, even if they lack clear information about her attractiveness, age, and marital status.

The second goal of the present research was to investigate if men's cognitive performance will decrease if they merely anticipate an interaction with a woman: a situation that does not require actual impression management. From a theoretical point of view, this question is interesting, as previous research suggests that certain types of interactions are cognitively taxing because they require people to manage their impressions and coordinate the interaction to make it run smoothly (Finkel et al., 2006). In the study by Karremans et al. (2009), men's cognitive performance decreased after they had been talking to and interacting with an attractive young confederate or fellow student for five to seven minutes. In this situation, men could extensively monitor and strategically adjust their verbal and nonverbal behavior during the interaction, and they had to exert effort to make the interaction run smoothly and override habitual or dispositional responses in order to make the desired impression (Vohs et al., 2005). This study suggests that interacting with a woman can be cognitively taxing for men as the males are expending their cognitive resources during the interaction on making a good impression, resulting in reduced cognitive resources to perform well on a subsequent task (Karremans et al., 2009).

Would an anticipated interaction lead to a similar cognitive impairment effect? If only actively making a good impression would cause the cognitive impairment effect, we should not expect this effect to occur in the case of an anticipated interaction with a woman. However, we reason that there may be processes related to impression management that can spontaneously be induced when anticipating an interaction with a woman, and these processes may also be cognitively taxing. In Tolstoy's novel, Levin thought about Kitty, the girl he would have to talk to later on, and practiced the interaction with her while walking to the pond to meet her. It seems likely that, when anticipating an interaction with a woman, men likewise try to envision their interaction partner and estimate which kind of impression they would like to make on her. Moreover, they may also envision how they will try to impress her. Relatedly, males may feel anxious when thinking about an upcoming interaction (as Levin did), which may negatively affect cognitive performance (cf. Richeson \& Shelton, 2003). Thus, psychological processes related to, or in the service of, impression management may hinder cognitive performance on other tasks.

In sum, although research suggests that men's cognitive performance decreases after an interaction with an attractive woman because they try to make a good impression on her, it is 
unclear if having a pseudo-interaction or anticipating an interaction will yield the same effects. This question is interesting because such interactions are highly prevalent in the age of internet, mobile phones, and instant messaging and because such interactions lack some of the characteristics (i.e., often little or no information about the interaction partner; no possibility for actual impression management in case of the anticipated interaction) that have been implied in explaining previous results showing that interacting with a woman can impair men's cognitive performance (Karremans et al., 2009).

We conducted two studies to address these issues. In Study 1, we investigated if men's cognitive performance would decrease after a pseudo-interaction in which men lacked clear information about the woman's mate value. In this study, men were told that they were being observed by a female experimenter while doing a task. In Study 2, we investigated if the cognitive impairment would occur for males in a situation in which they could not actually engage in impression management. In this study, men merely anticipated having a pseudo-interaction with a woman later on. The situation we created in both experiments was fairly neutral ${ }^{1}$ : participants were told that they participated in an experiment about language, and their supposed interaction partner was an experimenter who would send them a message to let them know that they could start the task. We expected that men's, but not women's, cognitive performance would decrease after they had a pseudo-interaction with, or anticipated an interaction with, someone from the opposite sex.

\section{Study 1}

In Study 1, participants completed a task in which a male or female experimenter was ostensibly observing them and sending them instant messages. Importantly, our participants had no information regarding the attractiveness of their observer. ${ }^{2}$ Thus, this interaction was a pseudo-interaction in the sense that the only information participants had about their interaction partner was his or her name, and participants did not have face-to-face-contact with their interaction partner. After this

\footnotetext{
1 We used an instant messaging-manipulation in the current experiment. Though some participants might have used instant messaging to communicate with dates and might thus associate instant messaging with sex, we do not think the instant messaging-manipulation primed participants with sex, as instant messaging is mostly used to strengthen social networks (Grinter, Palen, \& Eldridge, 2006).

2 Although participants did not receive any information about the observer, participants might have assumed that the observer was a young person (e.g., a student) because the experiment was conducted at a university and because the experimenter that led them to their cubicle was a young person. As in many situations in everyday life, participants could have made educated guesses about the observer's age based on contextual information, but they did not have any actual information about the observer's mate value besides this.
}

“pseudo-interaction," we measured participants' level of cognitive functioning to investigate if men's cognitive performance was impaired if they thought they had been observed by a female (compared to a male) experimenter.

\section{Method}

\section{Participants and Design}

A total of 71 students of the Radboud University Nijmegen (39 women) participated in exchange for partial course credit or $€ 4$ (approximately \$5.50). Participants' mean age was 21 years and all were native Dutch speakers, had a heterosexual orientation, and were not colorblind. Participants were randomly assigned to be observed by a male or female experimenter (Bas or Lisa). The study had a 2 (participant sex) $\times 2$ (observer sex) between subjects-design.

\section{Procedure}

Participants were escorted to their cubicle by an experimenter of their own sex. ${ }^{3}$ The experiment consisted of three parts. First, as a baseline measure of cognitive functioning, they completed a Stroop color naming-task (Stroop, 1935), a task in which participants have to ignore the semantic meaning of a word and focus on its color. Next, to create a pseudo-interaction with a woman, or a man, participants were given a task in which they were led to believe that they were observed either by a woman or by a man. Finally, after the task, participants again completed the Stroop task which served as our main dependent variable.

After participants completed the baseline measure of cognitive functioning, a Stroop task consisting of one practice block and five test blocks (five words per block), they started the "lip reading task." Participants read short Dutch words out loud in front of a webcam, ostensibly to collect stimulus materials for a study on lip reading. In reality, the only goal of this task was to give participants the impression that they were interacting with an experimenter (the observer). Before the "lip reading" task started, a chat window popped up in which an observer (named Bas or Lisa) sent the participants instant messages. In these messages, the task was explained and participants were told that the experimenter would monitor them during the task. The messages were fully computerized (there was no real Bas or Lisa) and participants could not respond to them. The chat window (including the observer's name and messages) remained visible on screen during the entire lip reading task.

\footnotetext{
${ }^{3}$ Participants were led to the cubicle by an experimenter of their own sex to insure that they were not depleted immediately prior to the interaction. Though this is important, a disadvantage of this procedure is that we cannot rule out that men's cognitive performance only decreases after a pseudo or anticipated interaction with a woman if they have interacted with a man first. This seems highly unlikely, however, as we do not have any theoretical reasons to expect such an effect.
} 


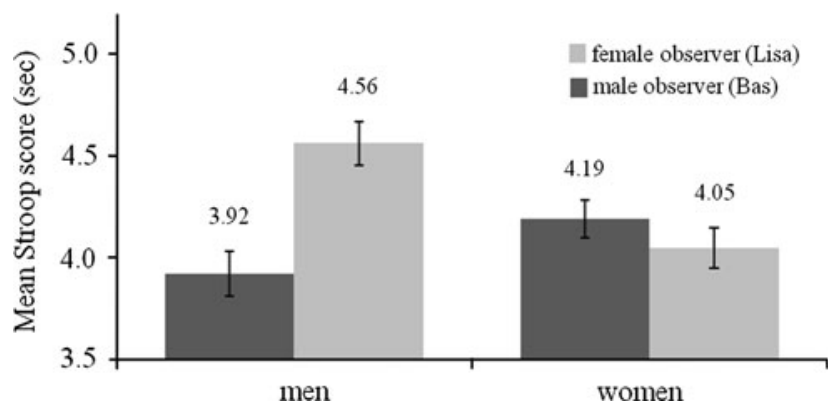

Fig. 1 Mean posttest Stroop score in seconds for male and female participants after a pseudo-interaction with a male observer (Bas) or a female observer (Lisa) (Study 1). Stroop pretest was used as a covariate to control for baseline differences in cognitive control

No picture was included, so the sex of the observers could only be deduced from the observer's name, which was either a typical Dutch male name (Bas) or a typical Dutch female name (Lisa). After the lip reading task, participants completed another Stroop task (Stroop posttest).

\section{Results and Discussion}

Mean latencies were computed across all five test blocks for both the Stroop pretest and the Stroop posttest. Two trials were removed because their latency exceeded the mean block latency by more than three SDs. An ANOVA was conducted with the mean latency of the Stroop posttest as the dependent variable and participant sex and observer sex as predictors. To control for individual differences in baseline cognitive functioning, the mean latency of the Stroop pretest was used as a covariate.

We expected that men would perform worse on a Stroop-task after a pseudo-interaction with someone of the opposite sex than after a pseudo-interaction with someone of their own sex. In line with this prediction, there was a significant interaction between participant sex and observer sex, $F(1,70)=15.08, p<.001$, $\eta_{p}^{2}=.19$. As depicted in Fig. 1, a one-tailed test showed that male participants performed worse on the Stroop task after they were allegedly observed by a woman, $M=4.56, S D=0.11$, as compared to when observed by a man, $M=3.92, S D=0.11$, $F(1,70)=8.39, p<.001$. The Stroop performance of female participants was not influenced by the sex of the observer $(F<1)$. In line with previous findings by Karremans et al. (2009), men's cognitive performance declined after an "interaction" with a woman, even though there was no actual faceto-face contact with the woman, and participants did not have clear information about the woman's looks.

\section{Study 2}

In Study 2, we investigated if men's cognitive performance would be negatively affected by merely anticipating an interaction with a woman. To examine this question, male and female participants were subtly told that they would be interacting with either a man or a woman. However, before the interaction would take place (which in fact did not take place), their cognitive performance was measured. Thus, whereas in Study 1 we demonstrated that the cognitive impairment effect occurred even without information about the woman's attractiveness, and when impression management opportunity was very low during a pseudo-interaction, in Study 2 participants did not interact with the other at all.

\section{Method}

\section{Participants and Design}

A total of 90 participants (64 women) of the Radboud University Nijmegen participated in the study in exchange for partial course credit or $€ 5$ (approximately \$7). Participants' mean age was 21 years and all were native Dutch speakers, had a heterosexual orientation, and were not colorblind. Participants were randomly assigned to anticipate being watched by a male or female observer (Daan or Danielle). The study had a 2 (participant sex) $\times 2$ (observer sex) between subjects-design .

\section{Procedure}

As in Study 1, participants were escorted to a cubicle by an experimenter of their own sex, ostensibly to collect stimulus materials for a study on lip reading. The experimenter explained the study to the participants: they would start with a Stroop color naming-task and then proceed to the "lip reading" task. In the lip reading task, participants would read words out loud in front of a webcam, while being observed by another experimenter sitting in an adjacent cubicle, called Daan or Danielle. This observer, participants were told, would turn on the webcam and send them an instant message when they could start the lip reading task. In reality, we only gave this instruction to create the expectation for participants that they would be observed by a male or female observer later on in the study. Thus, the manipulation of observer sex consisted of the experimenter referring to the observer with a typically male or female name (Daan or Danielle) and as he or she. After the instruction, the experimenter left the cubicle and participants completed a Stroop color naming-task (the same task as in Study 1) to measure cognitive functioning.

\section{Results and Discussion}

As in Study 1, mean latencies were computed across all five test blocks. One trial was removed because it exceeded the mean block latency by more than three SDs. An ANOVA was conducted with the mean Stroop latency as a dependent variable and participant sex and observer sex as predictors. 


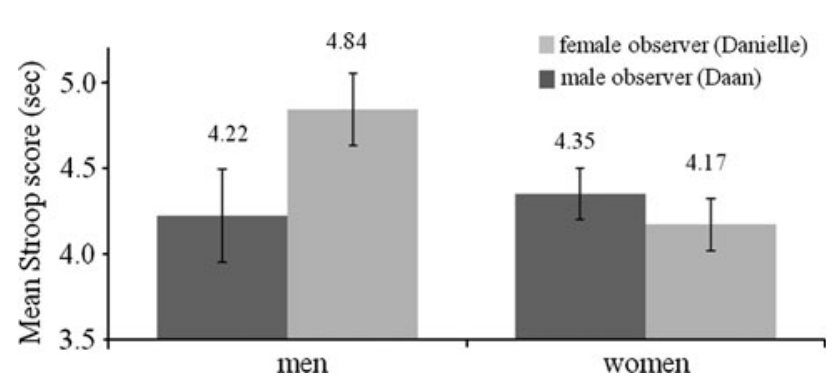

Fig. 2 Mean Stroop score in seconds for male and female participants after anticipating an interaction with a male observer (Daan) or a female observer (Danielle) (Study 2)

We expected that male (but not female) participants would perform worse on the Stroop task if they anticipated a mixed-sex interaction than if they anticipated a same-sex interaction. In line with our expectations, there was a significant observer sex $\times$ participant sex interaction, $F(1,89)=4.04, p=.05$, $\eta_{p}^{2}=.05$. As depicted in Fig. 2, a one-tailed test showed that male participants performed worse on the Stroop task when they expected observation by a woman, $M=4.84, S D=0.21$, as compared to when expecting observation by a man, $M=4.22$, $S D=0.27, F(1,89)=3.29, p=.04$. The Stroop performance of female participants was not influenced by the sex of the observer $(F<1)$. Thus, the anticipation of a mixed sex-interaction seemed enough to influence men's performance on a cognitive task. As in Study 1, this effect occurred even though participants did not have clear information about the woman's mate value.

\section{General Discussion}

The present research showed that men's cognitive performance declined after they engaged in a pseudo-interaction with a woman (Study 1 ) or after they merely anticipated interacting with a woman (Study 2). These findings extent previous research by suggesting that actually interacting with a woman was not a necessary prerequisite for the cognitive impairment effect in men to occur. Men seem so strongly attuned to mating opportunities that they were influenced by rather subtle cues to a woman, even in the absence of clear information about her. Casually mentioning a female instead of a male name was sufficient to impair men's cognitive performance. Outside of the laboratory, men frequently anticipate interactions or engage in pseudo-interactions in which they have limited information about their interaction partner. Thus, the present research suggests that the cognitive impairment effect for males can occur in more situations than previously assumed: men's cognitive performance might be affected if they are talking to a woman on the phone (or already before that, while they were waiting for her phone call), if they are chatting with a woman online or if they are sitting in the waiting room of their new, female, doctor.
Research on high-maintenance interactions suggests that certain types of interactions are cognitively taxing because they require people to manage their impressions and coordinate the interaction (Finkel et al., 2006). These studies suggest that interacting with a woman can be cognitively taxing for men (Karremans et al., 2009) and that interacting with African Americans can be cognitively taxing for high prejudice whites because they have to exert effort as not to appear prejudiced (Richeson \& Shelton, 2003). As the term suggests, it has so far been assumed that high maintenance interactions are cognitively taxing due to factors within the interaction. The present study is the first to show that cognitive impairment effects can occur in the absence of an actual interaction, raising the interesting possibility that merely anticipating other types of high maintenance interactions might also affect people's cognitive performance. Thus, it might also be the case that, for high prejudiced whites, merely anticipating an interaction with an African American can already affect their cognitive resources. Because people more strongly rely on stereotypes if they have fewer cognitive resources available (Gordijn, Hindriks, Koomen, Dijksterhuis, \& Van Knippenberg, 2004), knowing that one has to try to appear non prejudiced later on might have the paradoxical effect of increased reliance on stereotypes because high prejudice whites' cognitive resources are already depleted before they even start interacting with an African American.

Though impression management seems to be the most likely explanation for the cognitive impairment effect, more research is needed to gain insight into the exact processes that lead to a decrease in men's cognitive resources. Impression management is a complex process that consists of different actions (Leary, 1995), such as sizing up an interaction partner, thinking about the image one would like to portray to that specific interaction partner, and monitoring if one's behavior fits that impression. In the current study, men's cognitive performance might have decreased because they were busy thinking about the upcoming interaction and their interaction partner. It is also possible that men felt anxious when thinking about the upcoming interaction or that they chose to allocate less resources to the Stroop task in order to "save" cognitive resources for the actual interaction to be able to make a good impression on their interaction partner later on. Thus, though the present research suggests that impression management is the cause of the cognitive impairment effect, future research should investigate exactly which impression management processes cause the effect, and if there are any other processes (e.g., an increase in testosterone upon seeing a woman's name) that might play a role in causing or exacerbating the effect. Another suggestion for future research would be to investigate if the cognitive impairment effect also occurs for gay men. Although we suggest that men's, but not women's, cognitive performance diminishes after a pseudo-or anticipated interaction because evolutionary pressures shaped men to be more likely to sexualize fairly neutral situations, we cannot rule out that the sex difference is caused by male-typical 
socialization (especially when it relates to evolutionary novel situations, such as instant messaging). Studying if men show the same effects when anticipating an interaction with a woman, regardless of sexual orientation, would help us to gain more insight in this issue.

In sum, the present research suggests that men's, but not women's, cognitive performance diminishes if they think they interact with, or anticipate interacting with, someone from the opposite sex. Although more research is needed to investigate the exact processes that play a role in the cognitive impairment effect, and to study if it occurs in other groups of participants, such as in gay men, the present research gives us a little more insight in why Levin started stuttering by the time he reached the pond. Even the most subtle form of exposure to a potential mate can diminish men's cognitive performance, even if she is nothing more than a name on a computer screen.

Acknowledgments We thank Else Ouweneel for her contributions to the design of Study 1. Moreover, we would like to thank several anonymous reviewers for their helpful comments and suggestions. The present research was partly funded by a research grant (VENI Grant, No. 451-04-104) from the Dutch Association of Scientific Research (NWO).

Open Access This article is distributed under the terms of the Creative Commons Attribution Noncommercial License which permits any noncommercial use, distribution, and reproduction in any medium, provided the original author(s) and source are credited.

\section{References}

Baumeister, R. F., Catanese, K. R., \& Vohs, K. D. (2001). Is there a gender difference in strength of sex drive? Theoretical views, conceptual distinctions, and a review of relevant evidence. Personality and Social Psychology Review, 3, 242-273.

Baumeister, R. F., DeWall, C. N., Ciarocco, N., \& Twenge, J. M. (2005). Social exclusion impairs self-regulation. Journal of Personality and Social Psychology, 88, 589-604.

Finkel, E. J., Campbell, W. K., Brunell, A. B., Dalton, A. N., Scarbeck, S. J., \& Chartrand, T. L. (2006). High-maintenance interaction: Inefficient social coordination impairs self-regulation. Journal of Personality and Social Psychology, 91, 456-475.

Garret, R. K., \& Danziger, J. N. (2008). IM = interruption management? Instant messaging and disruption in the workplace. Journal of Computer-Mediated Communication, 13, 23-42.
Gordijn, E. H., Hindriks, I., Koomen, W., Dijksterhuis, A., \& Van Knippenberg, A. (2004). Consequences of stereotype suppression and internal suppression motivation: A self-regulation approach. Personality and Social Psychology Bulletin, 30, 212-224.

Grinter, R. E., Palen, L., \& Eldridge, M. (2006). Chatting with teenagers: Considering the place of chat technologies in teen life. ACM Transactions on Computer-Human Interaction, 4, 423-447.

Haselton, M. G. (2003). The sexual overperception bias: Evidence of a systematic bias in men from a survey of naturally occurring events. Journal of Research in Personality, 37, 34-47.

Haselton, M. G., \& Buss, D. M. (2000). Error management theory: A new perspective on biases in cross-sex mind reading. Journal of Personality and Social Psychology, 78, 81-91.

Hu, Y., Wood, J. F., Smith, V., \& Westbrook, N. (2004). Friendship through IM: Examining the relationship between instant messaging and intimacy. Journal of Computer-Mediated Communication, $10,38-48$.

Karremans, J. C., Verwijmeren, T., Pronk, T. M., \& Reitsma, M. (2009). Interacting with women can impair men's cognitive functioning. Journal of Experimental Social Psychology, 45, 1041-1044.

Leary, M. (1995). Self-presentation: Impression management and interpersonal behavior. Boulder, CO: Westview Press.

Richeson, J. A., \& Shelton, J. N. (2003). When prejudice does not pay: Effects of interracial contact on executive function. Psychological Science, 14, 287-290.

Ronay, R., \& von Hippel, W. (2010). The presence of an attractive woman elevates testosterone and physical risk taking in young men. Social Psychological and Personality Science, 1, 57-64.

Stroop, J. R. (1935). Studies of interference in serial verbal reactions. Journal of Experimental Psychology, 18, 643-662.

Tolstoy, L. (2003/1877). Anna Karenina (R. Edmonds, Trans.). Harmondsworth: Penguin Classics.

Van den Bergh, B., \& Dewitte, S. (2006). Digit ratio (2D:4D) moderates the impact of sexual cues on decisions in ultimatum games. Proceedings of the Royal Society: Biological Sciences, 273, 2091-2095.

Van den Bergh, B., Dewitte, S., \& Warlop, L. (2003). Bikinis instigate generalized impatience in intertemporal choice. Journal of Consumer Research, 35, 85-97.

Vohs, K. D., Baumeister, R. F., \& Ciarocco, N. J. (2005). Self-regulation and self-presentation: Regulatory resource depletion impairs impression management and effortful self-presentation depletes regulatory resources. Journal of Personality and Social Psychology, 88, 632-657.

Wan, E. W., \& Sternthal, B. (2008). Regulating the effects of depletion through monitoring. Personality and Social Psychology Bulletin, 34, $32-46$.

Wilson, M., \& Daly, M. (2004). Do pretty women inspire men to discount the future? Proceedings of the Royal Society B, 271, 177179. 